\title{
Revealing pelagic habitat use: the tagging of Pacific pelagics program
}

\section{Idées sur l'utilisation de l'habitat pélagique : le programme de marquage de pélagiques dans le Pacifique}

\author{
Barbara A. Block ${ }^{\mathrm{a}, *}$, Daniel P. Costa ${ }^{\mathrm{b}}$, George W. Boehlert ${ }^{\mathrm{c}}$, Randy E. Kochevar ${ }^{\mathrm{d}}$ \\ ${ }^{a}$ Stanford University, Tuna Research and Conservation Center, Hopkins Marine Station, Oceanview Blvd., Pacific Grove, CA, 93950, USA \\ ${ }^{\mathrm{b}}$ Long Marine Laboratory, 100 Shaffer Road, University of California, Santa Cruz, CA, 96060, USA \\ ${ }^{\mathrm{c}}$ Oregon State University, Hatfield Marine Science Center, Newport, OR, 97365, USA \\ dMonterey Bay Aquarium, 886 Cannery Row, Monterey, CA, 93940, USA
}

Received 14 July 2002; received in revised form 10 October 2002; accepted 15 October 2002

\begin{abstract}
Tagging of Pacific pelagics (TOPP) is a pilot program of the Census of marine life (CoML) that will lead to understanding of pelagic habitat use by marine vertebrates and large squid in the North Pacific. Taking a multispecies approach, the TOPP project will use a range of electronic tag technologies to put the distribution and behavior of pelagic organisms in the context of the oceanography of the North Pacific. Tag-bearing animals will be used as autonomous ocean profilers to enhance sparse oceanographic observations for vast ocean regions. These autonomous ocean samplers will provide unprecedented coverage of the water column structure of the North Pacific. The temporal and spatial data generated by this project will provide an "organism-eye" view of several interactive oceanic regimes in the North Pacific. Twenty target species, including tunas, sharks, pinnipeds, cetaceans, seabirds, and marine turtles, will be monitored with electronic tags. Animal-collected oceanic data will be assimilated into global ocean databases, complement traditional methodologies and be used to help validate nearshore, regional, and basin scale ocean models. As more environmental information is gathered and delivered from the tagged animals, new insights will be obtained about their individual behaviors, as well as how diverse species have separately evolved to forage, reproduce, and survive in the vast pelagic environment. This multi-disciplinary approach will allow a novel merger of biological and physical data to provide a new understanding of the relationship between the movements and behaviors of marine organisms and oceanographic processes in the eastern North Pacific.
\end{abstract}

(c) 2002 Ifremer/CNRS/IRD/Éditions scientifiques et médicales Elsevier SAS. All rights reserved.

\section{Résumé}

Le Marquage de pélagiques dans le Pacifique est un des programmes pilotes du Recensement de la vie marine (CoML) qui doit conduire à mieux comprendre l'utilisation de l'habitat pélagique par des vertébrés marins et les grands céphalopodes du Pacifique Nord. Grâce à une approche plurispécifique, le programme Marquage de pélagiques dans le Pacifique utilisera toute une gamme de marques électroniques pour déterminer la distribution et le comportement d'organismes pélagiques. Les animaux marqués serviront de «profileurs » océaniques autonomes pour améliorer les observations rares pour l'océan du large. Ils fourniront une couverture sans précédent de la structure de la colonne d'eau dans le Pacifique Nord. Ces données spatiales et temporelles constitueront la vision par un véritable « organisme-œil » des régimes océaniques interactifs de cette zone. Une vingtaine d'espèces-cibles, incluant des thons, des requins, des pinnipèdes, des cétacés, des oiseaux de mer et des tortues de mer sera ainsi suivie. Les données collectées par ces animaux seront intégrées au sein des bases de données océaniques, complétant l'approche traditionnelle et permettant de valider des modèles à l'échelle de la zone côtière, de la région et du bassin océanique. Ceci permettra l'émergence de nouveaux concepts sur les comportements individuels, aussi bien que sur la manière dont les diverses espèces ont évolué de manière séparée pour se nourrir, se reproduire et survivre dans l'immense environnement pélagique. Cette approche multidisciplinaire conduira à des données physiques et biologiques nouvelles, base d'un renouvellement de la

\footnotetext{
* Corresponding author.

E-mail address: bblock@stanford.edu (B.A. Block).
} 
compréhension des relations entre les déplacements et les comportements des organismes marins et des mécanismes océaniques dans le Pacifique nord-est.

(C) 2002 Ifremer/CNRS/IRD/Éditions scientifiques et médicales Elsevier SAS. Tous droits réservés.

Keywords: Pelagic habitat; Tagging; Pelagic organism

Mots clés: Milieu pélagique; Marquage; Organismes pélagiques

\section{Introduction}

The geographic and depth distributions of pelagic marine predators are poorly known. Pelagic animals have historically been a challenge to study due to their size, speed and range over the vast oceanic habitat. The difficulty of working with marine vertebrates in extreme environments far from land has made acquisition of data on their biology challenging. Assessment of movements, foraging habitat and breeding areas of marine megafauna remain technically difficult because most large, marine nekton are active, difficult to handle, and spend little (if any) time at or near the surface, thus remaining far from sight.

The tagging of Pacific pelagics (TOPP) pilot program of the Census of marine life (CoML) will use electronic tags to describe patterns of movement and behavior of marine vertebrates and large squid in the North Pacific. The primary objectives of the TOPP program are to understand animal movements and aggregations in the context of the complex and varying North Pacific environment. The study will provide a framework for future management and conservation of these economically and ecologically valuable resources. TOPP will develop the tools (e.g., an oceanographic toolkit to improve the integration of biology with the physical environment) and the conceptual background necessary for using electronic tags in future multispecies tagging efforts in other locations. For many commercially important species (tunas, sharks), understanding habitat (structure, spawning sites, foraging locations, migratory routes and temporal and spatial movement patterns in relationship to the ocean environment) forms the foundation for future conservation and management of these valuable resources; for depleted or protected species, the same knowledge can aid in recovery. Most marine megafauna range over the vast expanses of the world's oceans. Building a fundamental knowledge of the temporal and spatial distribution of top predators in relation to oceanographic conditions, such as when and where multispecies aggregations occur and the seasonal variation of such movements, has tremendous importance for understanding the evolution and conservation of species.

Specifically, the TOPP program will address the following questions:

- How do top predators respond to the varying physical environment?

- How does habitat selection take place?
-Where are the migration corridors, and why?

-What are the topographical and other physical features that organisms use to chart their courses, or locate food concentrations?

- What are the regions of potential conflicts with human activities?

We will learn where sites of common aggregation occur (e.g., fronts, convergences or other causes of prey aggregations) and define favored migration corridors (Polovina et al., 2000; Hyrenbach et al., 2002). TOPP will also document the associations among members of the various pelagic or coastal assemblages and determine where and when they are most likely foraging. We will generate fundamental knowledge of how oceanic populations are structured temporally and spatially in relation to oceanographic features while observing how seasonal variations affect these patterns. Finally, the results from the electronic tagging of animals may enhance oceanographic models by collecting in situ physical data from organismal movements, covering areas of the world oceans that are rarely sampled by oceanographic vessels; these data can provide information about the water column unavailable from remote sensing satellites. Incorporation of animal-collected data into an integrated ocean model will help fill data gaps that can provide a better understanding of ocean atmosphere coupling and its role in meteorology and long term climate change. The temporal and spatial data generated by this project will provide an "organism-eye" view and detailed understanding of how marine animals from several tropic levels use distinct oceanic regions in the eastern Pacific.

\section{The importance of multidisciplinary science}

The TOPP project brings together a diverse range of expertise from researchers in academia, industry and government agencies. TOPP's activities regarding integration of biology with the physical environment are closely coordinated with several related ocean-monitoring initiatives. These include the Global Ocean Ecosystems Dynamics Program (GLOBEC) (Hofman et al., 2002) focus on physical-biological interactions and the Global Ocean Observing System (GOOS) program's goal to improve ocean data through diverse ocean observation systems. (Steele, 1998; Nowlin et al., 2001).

TOPP will use a variety of commercially available electronic tags, primarily archival and satellite-linked 
Table 1

There are four broad classes of electronic tags that are currently available or under development. The tags are shown with the types of data that can be collected. Archival tags are data logging tags that must be recovered to acquire the data, ARGOS satellite tags transmit the data via satellite, PSATs $\log$ data and then when released from the animal, pop up and transmit a data summary via ARGOS. Satellite-linked dive recorders log, process and then transmit a data whenever the animal reaches the surface

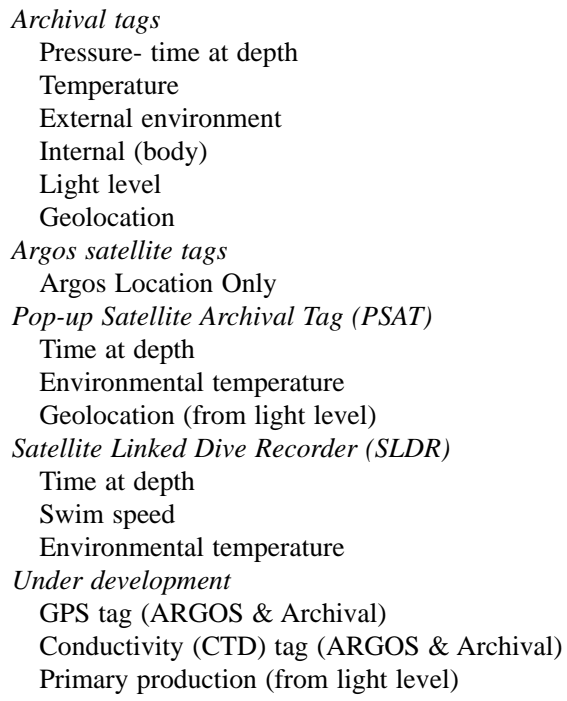

(Table 1), and is engaged in accelerating the availability and testing of tags and sensors that are currently under development. The development and testing of novel electronic tags (e.g., CTD, archival Global Positioning System (GPS), and primary productivity tags) on a variety of organisms was generally beyond the capability of any one laboratory or research group. Synergism has already occurred across disciplines-biologists and engineers are now incorporating suggestions from biological and physical oceanographers in the design and implementation of new tags. Working independently, and with little cross-fertilization between the two groups, the fish and marine mammal research communities have advanced and accelerated the development of electronic tags in the past 5 years. Smaller tags, increased memory and more sophisticated on-board processing of data are rapidly improving the information retrieved from the tags. The recent growth of interest in electronic tagging in the fish research community has led to rapid evolution of the archival and pop-up satellite tag technology. The TOPP project will create partnerships between marine mammal, seabird, fish and reptile researchers and between academia, industry and government to develop common approaches to tag development, utilization and data integration and analysis.

\section{Animals as ocean sensors}

An exciting, recent development from observing diving predators such as marine mammals, fish and birds has been the realization that electronic tag-bearing animals can be employed as autonomous ocean profilers to provide environmental observation data in diverse ocean regions (Wilson, 1992; Costa, 1993; Weimerskirch et al., 1995; McCafferty et al., 1999; Campagna et al., 2000; Boehlert et al., 2001; Block et al., 2001; Charrassin et al., 2002; Wilson et al., 2002). A significant advantage of tag-collected oceanographic data is that they are collected at a scale and resolution that matches the animals' behavior. When the biological and physical data are merged, a new understanding of the relationship between the movements and behaviors of marine organisms and oceanographic processes will become apparent (Figs. 1 and 2). As more environmental information is gathered and delivered from the tagged animals, new insights will be obtained about their individual behaviors, as well as how they respond to environmental variability on daily, seasonal, and inter-annual time scales. These insights will become apparent when tag-derived animal behavior data are combined with other environmental information-e.g., sea surface temperature, sea level and ocean color from remote sensing technologies, and output from ocean models. The TOPP program plans to tag 5000 animals from 20 distinct taxa (Table 2) to understand better the distribution of marine animals in their environments. For archival tagging on exploited species (tunas), deployment of thousands of tags is necessary for retrieval of significant amounts of data. The new animal-collected oceanic data will complement more traditional methodologies for assimilation into oceanographic models. The growing partnership between physical oceanographers and the TOPP program will provide a venue for animal acquired data to be incorporated into the operational oceanography community. The current limitation of meteorological and climate change models is our inability to accurately describe the heat budget of the ocean (ATOC Consortium, 1998). To this end, programs such as GOOS are developing novel approaches for large-scale sampling of the ocean environment. TOPP will provide a proof of the concept that oceanographic data collected by vertebrate animals can be assimilated into these programs. To this end, oceanographic data will be archived in CoML's Ocean Biogeographic Information System (OBIS) as well as in national (e.g., NODC) and international ocean data archives as quickly as possible after it is received and processed. Researchers involved in TOPP have provided the first concrete example of how such animalcollected data can be quality-controlled and archived in this manner (Boehlert et al., 2001).

\section{Importance of marine conservation, education and outreach}

From its inception, the CoML has fostered the idea that public education and outreach would be an integral part of its mission. The TOPP program has fully embraced this concept; one of the principal investigators (RK) is given the charge of developing a portfolio of education and outreach 


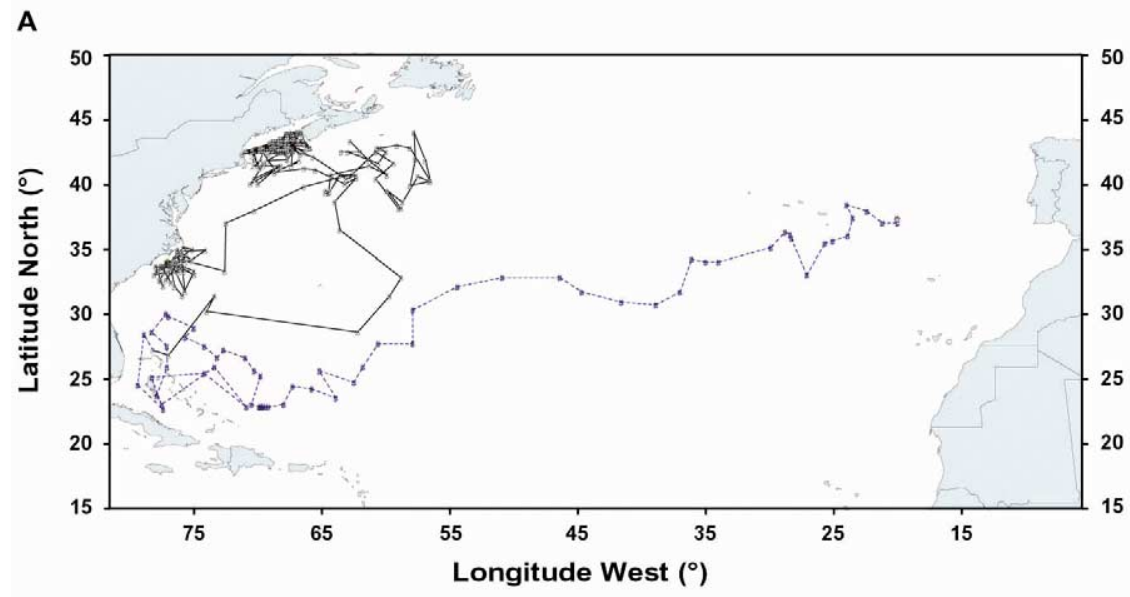

B

WC 98-521

External Temperature

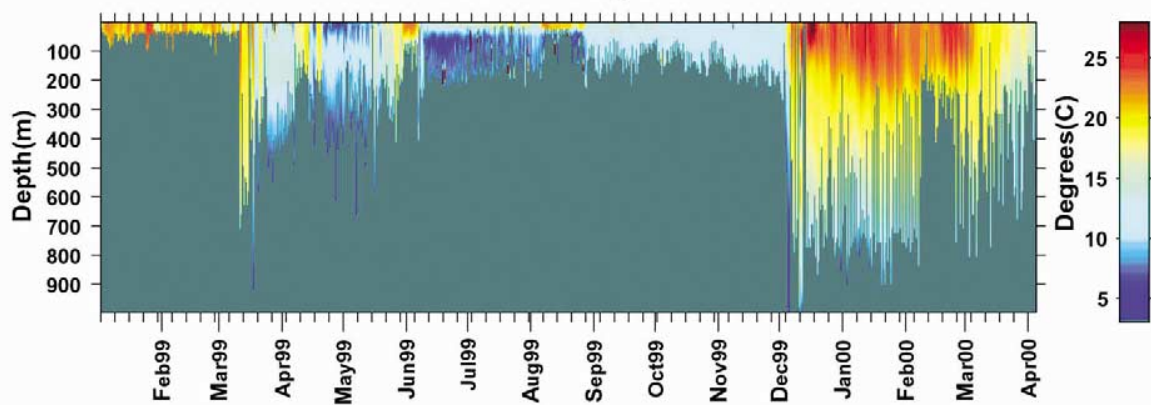

Fig. 1. (A) Position records based on light- and SST-based geolocation from the archival tagging of Atlantic bluefin tuna. The bluefin tuna was tagged and released offshore of North Carolina, USA with a Wildlife Computer MK7 tag in 1999. Fish 521 (released 01 Jan. 1999, $218 \mathrm{~cm}$ CFL) shows a western resident track in year one of the record, residing in Carolina and the Gulf of Maine. This track is typical of many archival tagged bluefin tuna released in the west Atlantic, followed by movements from the west Atlantic to the east Atlantic in year two (from Block et al., 2001). (B) Archival depth and temperature profiles reveal the daily structure of the water column for the duration of the mission.

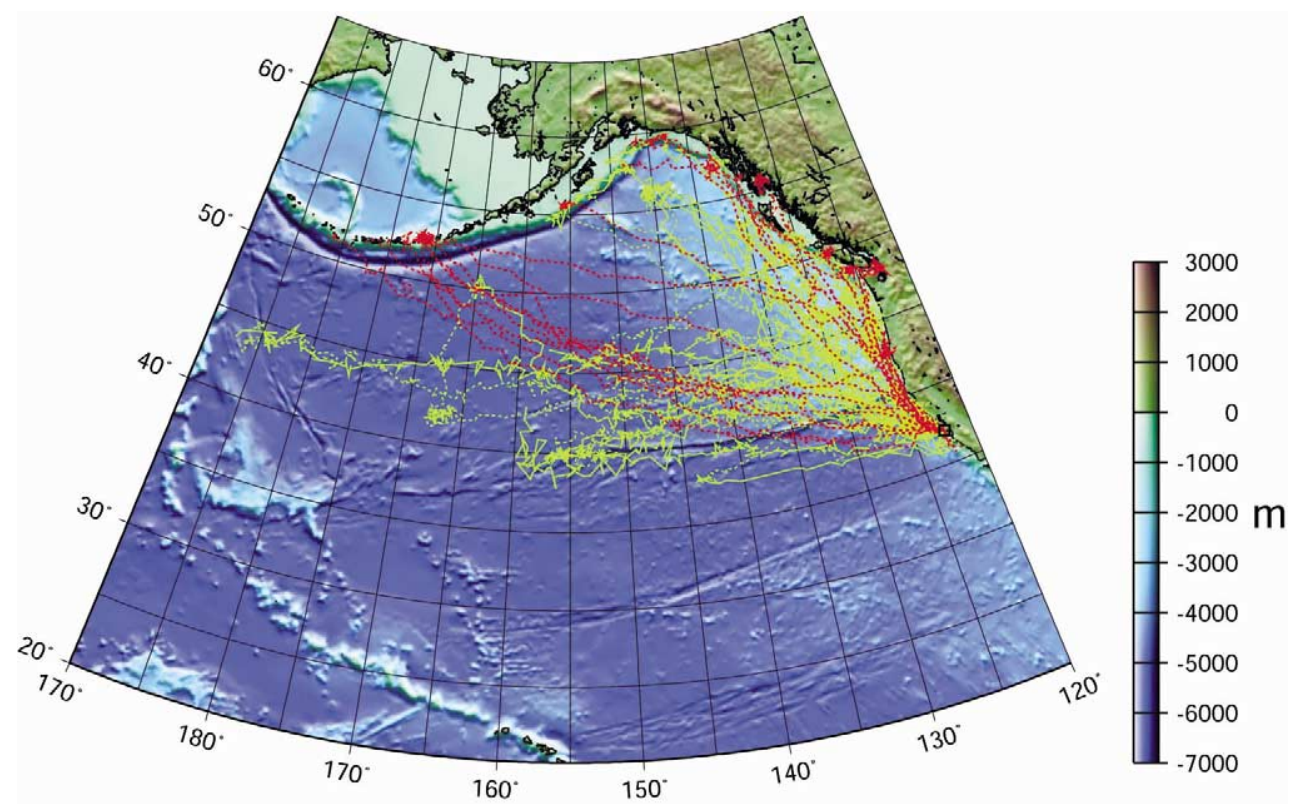

Fig. 2. Tracks of female (yellow) and male (red) northern elephant seals as they migrate across the Pacific Ocean from their rookery at Año Nuevo, CA (from Lebœuf et al., 2000). Tracks are derived from Argos-linked satellite transmitters. 
Table 2

TOPP species. The species in this list were chosen by the organismal working groups as having those biological and ecological attributes that meet the goals of the TOPP program

\begin{tabular}{ll}
\hline Air-breathing vertebrates & Fish, shark and squid \\
Leatherback turtle & Bluefin tuna \\
Loggerhead turtle & Yellowfin tuna \\
Black footed albatross & Albacore tuna \\
Laysan albatross & White shark \\
Elephant seals & Mako shark \\
California sea lions & Salmon shark \\
Blue, fin and humpback whales & Blue shark \\
Sperm whales & Common thresher shark \\
Pink and sooty shearwaters & Dosidicus gigas \\
& Mola mola \\
\hline
\end{tabular}

initiatives. The overall objective of these programs is to capture the imagination of the public by interpreting the importance and complexity of the open ocean environment and its key inhabitants. A unique feature of TOPP is that many of the animals studied already have a high visibility to the public and can act as "organismal ambassadors". One element of achieving this objective is the construction of a website (toppcensus.org) that will provide background information about the people, animals and technologies involved, as well as sharing ongoing developments as the program evolves and field studies are carried out. Additionally, TOPP has begun hosting education outreach workshops, attended by representatives of several public aquariums and science museums, educational researchers, media specialists and technology providers. Workshop attendees have proposed a series of programs to share TOPP through formal educational settings (e.g., classrooms), informal educational settings (e.g., public aquariums) and popular media (e.g., documentary and news radio, television and web outlets). In the coming months, these proposals will be refined and strategies developed to secure funding and personnel to move them into design/development and pilot testing phase.

\section{Organization and development of TOPP}

The use of electronic tags within the context of the CoML was examined at a TOPP workshop sponsored by the Sloan and Packard foundations in November 2000. For the first time, this workshop brought together engineers, oceanographers, researchers using electronic tag technologies on diverse organisms and manufacturers of the electronic tags. Although the organismal researchers were aware of each other prior to this meeting, they rarely interacted, simply because they tend to publish in discipline- or taxon-specific journals and attend different scientific meetings. At this workshop, it became clear that this large and diverse research community would benefit from closer collaboration and coordination of their research activities. An important aspect of the CoML is to develop approaches that have broad or general applicability. As electronic tags are an essential element of TOPP, the approaches developed and lessons learned can be easily transferred to other programs for use in any ocean basin on a wide array of large pelagic organisms.

As part of its planning phase, TOPP has convened a series of workshops to address the specific aspects of such a large interdisciplinary program. Topics have included selection of target organisms, the integration of oceanography and biology, data management and visualization, modeling of animal movements and oceanographic data, and education and outreach. Within these groups, TOPP PIs have assigned leadership roles to individuals with appropriate organismal expertise: sea turtles, sea birds, sharks, tuna, cetaceans, and pinnipeds or oceanographic expertise: remote sensing, data management, data visualization, data quality assurance and control. By assigning a leadership role to those with the greatest expertise chosen from a global community, the intellectual and team orientation of TOPP has been strengthened. Integration of experts in oceanographic regions of interest, climatology and modeling has brought an interdisciplinary approach to the program.

TOPP is in the final phase of program development with a final series of workshops to examine data visualization, data modeling and final organism logistics for late 2002 and early 2003. These workshops will complete the planning process and will provide the appropriate direction for the implementation of the full TOPP program. Workshop reports and planning documents can be obtained at the TOPP website, toppcensus.org. The final TOPP implementation plan will be developed and implemented by 2004 .

\section{TOPP species selection}

At the onset of TOPP species selection, our intention was to rely on species that in most cases had been previously investigated and proven as reliable animal platforms. Species were selected that added to two general themes: use of those species that would lead to trophic or species level aggregations with the objective being to find oceanic "hot spots." This would be analogous to finding what top predators are at the watering holes of the Serengeti plains but TOPP is examining the question in marine environs. TOPP researchers also plan to investigate species guilds, phylogenetically related taxa that use different regions of the North Pacific. The selection of TOPP candidate species was initially carried out during the November 2000 workshop. During this workshop, the two organismal working groups evaluated (i) air-breathing vertebrates and (ii) fishes, sharks and squid. These two groups proposed candidate species and the merits of each candidate species were discussed in detail at the workshop. While considerable progress was made during the first TOPP workshop, it was apparent that more discussion was needed among the organismal biologists to:

1. finalize the list of species; 
2. develop an implementation plan for specific species;

3. decide on the number and types of tags to be deployed;

4. consider the infrastructure required to facilitate communication between the various components of TOPP;

5. detail the logistics necessary for the various field components;

6. identify the timing and coordination of the varied elements of the program; and

7. identify the oceanographic data that would be required to understand habitat utilization;

8. identify the software tools and approaches that would be needed to integrate animal tag data with oceanographic information.

These issues were addressed in a series of independent organismal working group meetings that took place starting with the November 2000 workshop, and continued into 2002. The TOPP species lists have been further refined (Table 2) in these subsequent meetings of the smaller organismal groups.

An early tenet of the TOPP program was that the species selected for tagging should be proven platforms for successfully carrying tags; specifically, TOPP emphasizes the use of species that (1) had already been proven in previous projects at a single species level, and (2) would provide important and complementary information associated with the study area. Two foundation organisms, the northern elephant seal (Mirounga angustirostris) and the Pacific bluefin tuna (Thunnus thynnus orientalis), were proposed based on extensive pilot research already accomplished.

\section{Northern elephant seal}

Northern elephant seals offer a unique system to carry instrumentation and to collect environmental information of high oceanographic value (Costa, 1993; Le Bœuf et al., 2000; Boehlert et al., 2001). From California rookeries, this species ranges widely over the northeastern Pacific on foraging trips that last from 2 to 9 months (Delong et al., 1992). Migration patterns differ between the sexes; females may migrate throughout the northeastern Pacific, while males migrate to destinations along the continental margin from coastal Oregon north to the Aleutian Islands (Fig. 2) (Stewart and De long, 1990, 1995; Delong et al., 1992; Le Bouf, 1994). Females are at sea an average of 3 months during the spring migration and 7 months during the summer-fall migration. Northern elephant seals spend most of their time (80-90\%) at sea underwater (Fig. 5), exhibiting extremely long duration dives (mean $=22 \mathrm{~min}$, $\max =120 \mathrm{~min})$ with short surface intervals $(1-3 \mathrm{~min})(\mathrm{Le}$ Bœuf et al., 1988). Dives are routinely to $600 \mathrm{~m}$, but can be as deep as $1600 \mathrm{~m}$ (Delong and Stewart, 1991). With currently available tags, these animals have already proven to be capable of collecting large volumes of environmental temperature information throughout the central and eastern
North Pacific. The strong site fidelity and at sea survival makes elephant seals an idea animal for deployment of archival data loggers as there is a $90 \%$ instrument recovery rate. Northern elephant seals have been used to develop and test a variety of environmental sensors including acoustic archival data loggers (Fletcher et al., 1996; Burgess et al., 1998) and heart rate recorders (Andrews et al., 1997). These robust characteristics make northern elephant seals the best candidate as TOPP's major oceanographic animal platform, with a proven ability to reliably sample the water column (Boehlert et al., 2001). The data collected will be essential for improving hindcast models of the oceanography in the TOPP study areas. Long term (3-8 month) deployments of at least 300 tags composed of archival; GPS and CTD tags are planned. Northern elephant seal tagging will occur at the Año Nuevo rookery in Central California $(37.118 \mathrm{~N}$, 122.338W), the southern California Channel Islands, and on Guadalupe Island off Baja California.

\section{Northern bluefin tuna}

The successful deployment in recent years of implantable and pop-up satellite archival tags has rapidly enabled researchers to examine the movements of bluefin tunas in the Atlantic, Pacific and Southern oceans (Block et al., 1998a, b, 2001; Lutcavage et al., 1999; Kitagawa et al., 2000; Gunn and Block, 2001). These new techniques provide the major advances that will be necessary to understand the distribution of tunas in relation to their changing physical and biological environments (Fig. 3). Management agencies (e.g., ICCAT) are now using electronic tagging data to develop movement models with improved estimates of the distribution of Atlantic, Pacific and Southern bluefin tuna based on age, season and primary productivity. As more environmental information is gathered and delivered from the tagged animals, new insights will be obtained about their individual behaviors, as well as how they respond to environmental variability on daily, seasonal, and interannual time scales. To date, over 1100 electronic tags have been deployed on the three bluefin tuna species and more recently on bigeye tunas (Schaefer and Fuller, 2002). One program alone, the Tag-A-Giant effort in the Atlantic, has deployed over 650 tags (400 archival, 250 PSATs) on Atlantic bluefin ranging in size from 163 to $287 \mathrm{~cm}$ fork length. To date, in the Atlantic program, $24 \%$ of the first 2 years of deployed archival tags (1997 and 1999, $n=279$ ) have been recovered and $80 \%$ of the west Atlantic deployed pop-up satellite tags have reported successfully. Archival tags have provided a rich data set on the feeding and breeding migrations of Atlantic bluefin tuna (Fig. 1; Block et al., 2001). In the Pacific, Kitagawa et al. (2000) first deployed archival tags on Pacific bluefin and more recently, Marcinek et al. (2000) and Block et al. (unpublished data) have deployed Pop-up Satellite Individual Tag PSAT and archival tags, respectively, on 130 Pacific bluefin 
in the eastern Pacific with $100 \%$ success for the PSAT tags reporting. Prior to archival tagging Pacific bluefin, TOPP researchers extensively studied conventional tagged small bluefin to examine the ability to retrieve future implanted tags in the eastern Pacific. To date, $20 \%$ of the conventional tagged fish have been recaptured and a quarter of the recaptures have occurred near Japan waters. In August 2002, TOPP researchers deployed the newest models of archival tags in an effort to examine their capabilities and discern retreivability. Four archival tags have been recaptured within 4 months of release in the eastern Pacific by American and Mexican fishers. This has yielded some high resolution 1-min archival data on Pacific bluefin tuna in the eastern Pacific (Fig. 6) and bodes well for future TOPP tagging initiatives on Pacific bluefin tuna. Thus, the TOPP concept, tagging 1000 individual bluefin and potentially 1000 or more yellowfin and albacore tunas, will yield significant new data on the Thunnus clade in the eastern North Pacific and potentially throughout their range. New technology to ranch (hold and grow out) wild caught tunas for market located along the western North American coast will enable large-scale tagging of bluefin schools involving over 100 individuals per release. Tests of this tagging idea on a small scale, which emphasizes release in schools, have already begun (Marcinek et al., 2001; Block et al., unpublished results) with high success. Bluefin tuna tagged with PSAT tags and released from a tow pen simultaneously in Monterey all migrated south along the California and Mexican continental shelf (Fig. 6). One individual Pacific bluefin was recaptured 1 year after release off Baja, Mexico thus providing a second location point in the eastern Pacific after the initial Monterey release and pop-up satellite end point close to the California Coastal shelf several months post release. This indicates long term survivorship. The high success rate for recovering data from pop-up satellite tagged Pacific bluefin tuna (80-130 cm curved fork length) released in the wild indicates that retention of satellite tags is possible on tunas of relatively small sizes.

The TOPP list of organisms (Table 2) now includes a diverse group of species with interesting ecological linkages. Certain species have special characteristics like albatrosses (flight) that allow them to locate oceanic frontal features very rapidly (Hyrenbach et al., 2002). Some of these species (sperm whales, squid, and shearwaters) were included conditionally as the likelihood of successful tagging should be considered in further planning. For example, squid are a key trophic link in the North Pacific, but virtually nothing is known about their ecology and distribution. Thus, preliminary work during TOPP's preliminary phase will evaluate techniques useful for making squid a component species. Early success with pop-up satellite and archival tagging indicates that retrieval of data on the ecology of Dosidicus will be rapidly forthcoming.

The concept of studying a guild of closely related species that may use the oceanic environment in different ways was developed after the initial November 2000 workshop. This phylogenetic approach will allow us to compare and contrast how organisms of similar ancestry have diverged in their foraging ecology. From this perspective, we have developed a series of species guilds. These include lamnid and alopid sharks (white, salmon, mako and thresher sharks), tunas (yellowfin, bluefin and albacore), albatrosses (black footed and Laysan), shearwaters (pink footed and sooty), and rorqual whales (blue, fin and humpback whales). An additional benefit is that this guild approach will simplify the logistics involved. For example, within the California current, all these rorquals can be found in the same regions at similar times of the year. It is therefore possible to maximize the success of the tagging effort by using a single platform to tag all three species. Similarly, cruises for Pacific bluefin tuna provide ample opportunities to tag albacore tuna. By tagging both species simultaneously, shiptime costs are reduced.

TOPP researchers hope to learn more about multi-species interaction. While there is individual variation, blue whales show large concentrations near the Costa Rica Dome in mid-winter, followed by movements into the Gulf of California in spring and then off both Southern and Central California Coast in mid to late summer (Mate et al., 1999). Blue whales feed low in the food web, feeding exclusively on euphasiids (krill). Given that euphausiid abundance is related both to primary production and physical aggregation mechanisms, there are strong linkages with the physical oceanography (Fiedler et al., 1998). Moreover, their range overlaps with bluefin tuna that have often been found in similar regions at the same time with blue whales.

Fin whales can be studied using the same techniques as blue whales. They tend to occur farther offshore in some areas of the North Pacific and are not as common as blue whales in the coastal regions where logistics are more feasible. The feeding and breeding locations of humpback whales are also well documented. During late spring to early summer, they feed in the nutrient rich waters of the California current, southeastern Alaska and Prince William Sound. Individuals from Prince William Sound and southeastern Alaska migrate to Hawaii in the winter to breed (Calambokidis et al., 1996). Humpbacks that feed off California tend to migrate to the coast of Mexico and Central America to breed (Urban et al., 1999). Unlike blue and fin whales, humpback whales consume a more varied diet including fishes such as herring, anchovy and capelin. These prey items overlap with other TOPP organisms such as bluefin tuna and California sea lions, so there is an excellent opportunity to compare pelagic habitat use by rorquals and other TOPP species.

\section{Preliminary projects}

As a pilot project under the CoML, TOPP will demonstrate the unique attributes and capabilities of electronic tags 

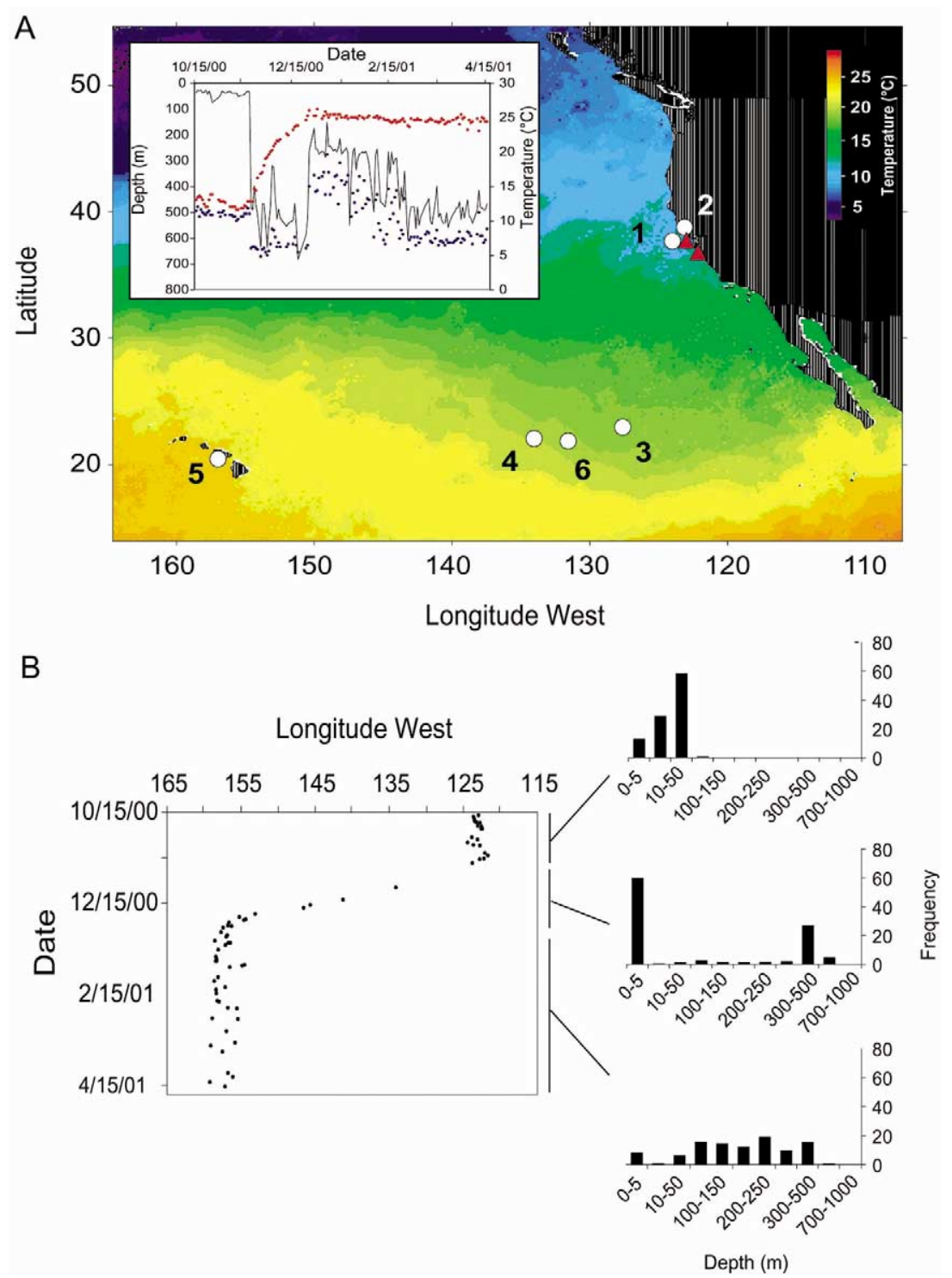

Fig. 3. Pop-up satellite archival tag tracks (Wildlife Computers PAT2 tag) from white sharks Carcharodon carcharius. (A) Release points are shown in red (SEFI, Southeast Farallon Islands; ANI, Ano Nuevo Island) and satellite pop-up endpoints are in white. The inset shows maximum depth (black line), maximum temperature (red), and minimum temperature (blue) from a pop-up satellite archival tag for the white shark that transited from the Farallon Islands to Hawaii (from Boustany et al., 2002). (B) Longitude data based on light-based geolocation and depth data from the white shark along the track from Central California to Hawaii.

as tools for examining the distribution and behavior of organisms in the North Pacific relative to the ocean environment. TOPP will utilize a series of technologies (pop-up satellite archival tags, satellite-linked data recorders, implantable archival and possibly GPS tags) to examine migrations and behavior of representative species in the major oceanic regimes of the North Pacific (Table 2). One of the major tenets of the program is to take advantage of recent successes of tagging programs that have pioneered the use of archival, data storage and satellite tags on the TOPP organisms (Block et al., 1998a, b, 2001; Mate et al., 1998, 1999; Le Bœuf et al., 2000; Kitagawa et al., 2000; Gunn and Block, 2001; Fernandez et al., 2001). We will build on the results of these studies as "pilot programs" for TOPP. However, it became clear in the November 2000 workshop that while these past projects have been quite successful, there are technological issues that need further examination or development prior to the deployment of large numbers of tags that will take place when TOPP is fully implemented. For example, archival tags are going through a variety of changes that include reduction in size, increase of memory, and significant changes associated with the external sensor stalk in some cases. New techniques, such as the use of single position only tags on dorsal fins of sharks (Fig. 4), are emerging as a more active mode of tracking than previous techniques (PAT tags). Tags that utilize the GPS to precisely determine location, are under development, as well as those that incorporate a salinity sensor (CTD). These new tags and tag software must be evaluated and field-tested under controlled experimentation 


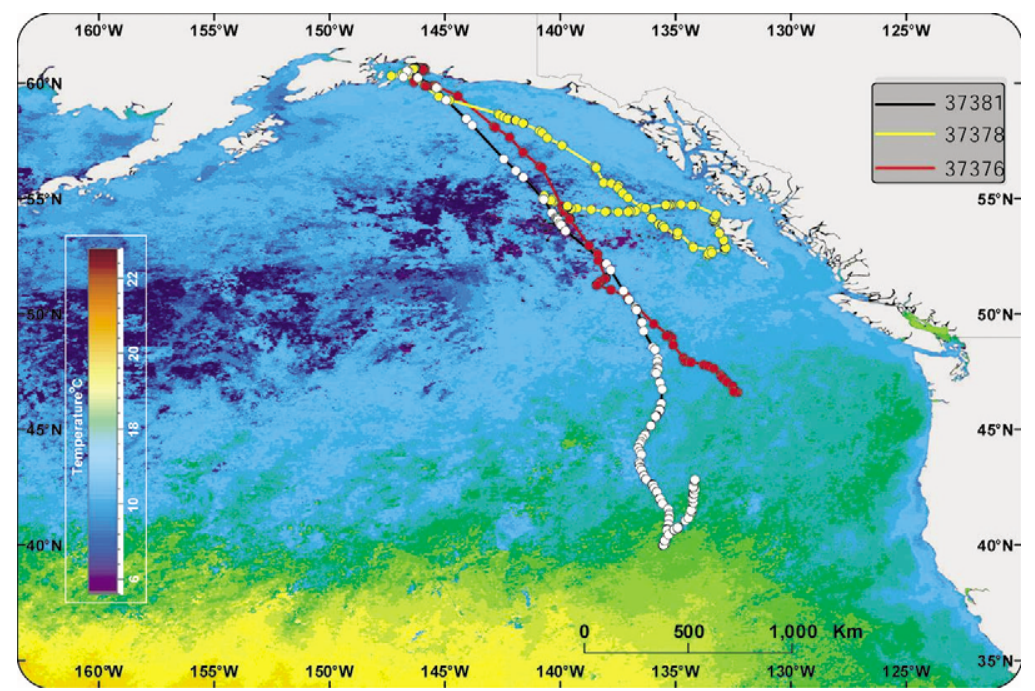

Fig. 4. Tracking of salmon sharks with dorsal fin satellite position only tags (Wildlife Computers SPOT Tag). Three salmon sharks were released in July 2002 from Prince William Sound with Spot1 tags attached to the dorsal fin. This technique has been used reliably on salmon and blue sharks. The image is overlaid over an SST composite from the same period (data from Weng, Holts and Block, unpublished).

prior to inclusion in TOPP. In addition, at the TOPP workshop, several manufacturers provided information about advances in tag technology and new prototypes of existing tags. Many of the tags provide promising advances in concept and design; however, all require basic fieldtesting on marine animal platforms for evaluation and calibration.

To this end, the TOPP program has received funding from a variety of sources (Sloan and Packard Foundations, National Oceanographic Partnership Program, California Sea Grant, NOAA, UC Coastal ocean health initiative) to
(1) test new generations of existing tags or emergent tag technology and (2) develop new tags and sensors and to begin the development of approaches and the software necessary to facilitate the visualization and synthesis of tag-collected data with oceanographic data; we refer to such a software system as the "TOPP oceanographic toolkit". These development efforts are designed to address specific issues that need to be evaluated prior to the full implementation of TOPP. Pilot experiments will focus on captive animal tagging or experiments in the wild such as translocations. At the same time, efforts are underway to improve

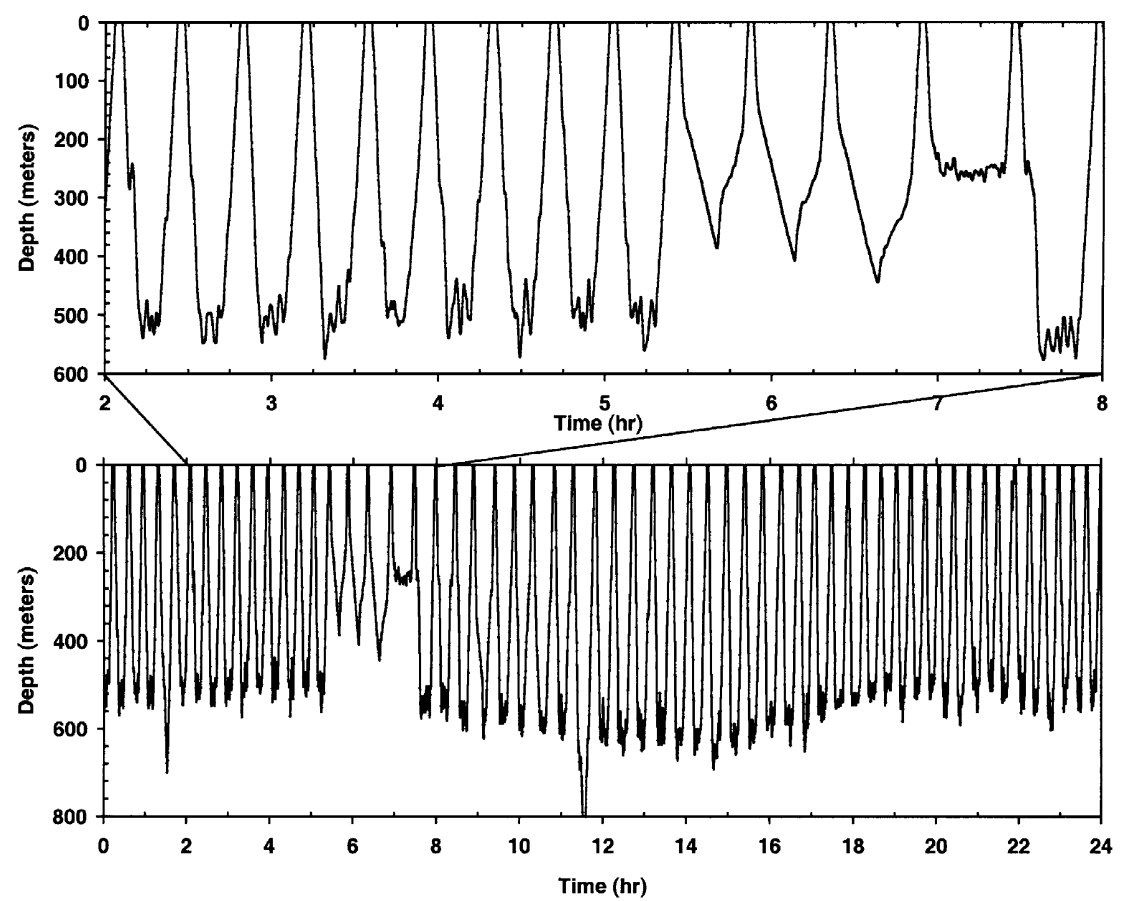

Fig. 5. Time at depth profile obtained with an archival data logger from a northern elephant seal. The bottom image is a typical 24-h section of a dive record from a female northern elephant seal. The upper image is an expanded 6-h section of this record showing the transition between dives that are thought to be foraging and dives that are thought to be where processing of food occurs. (See Crocker et al., 1997 for details). 
A
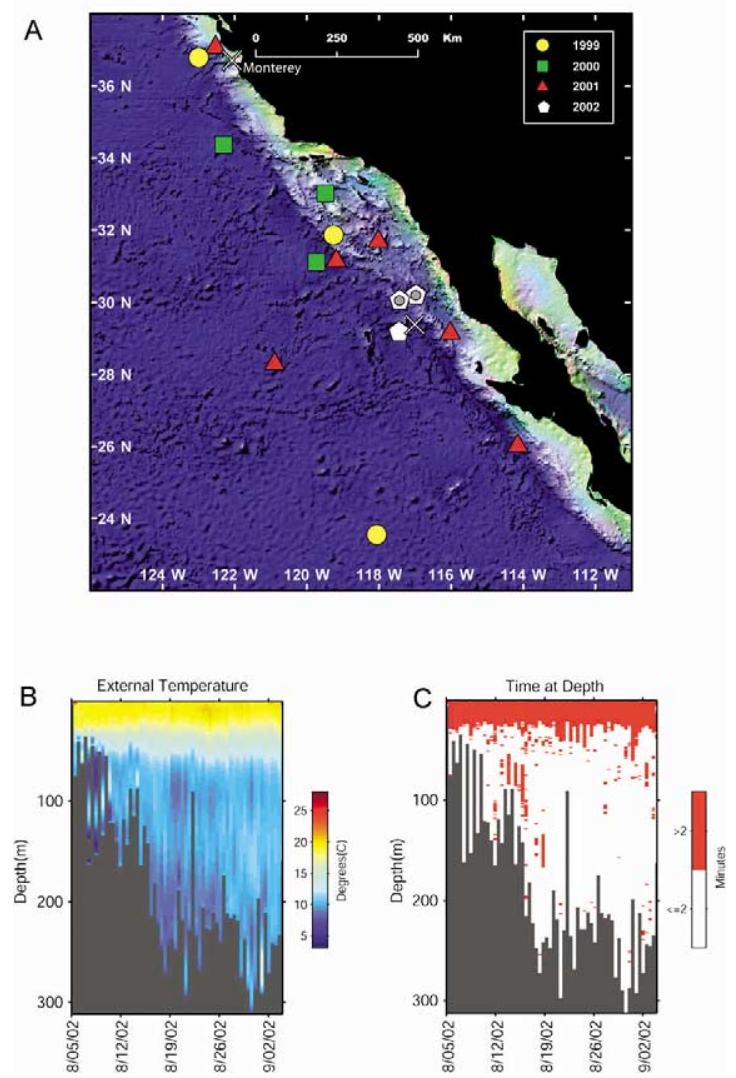

Fig. 6. Pop-up satellite archival tagging of small $(80-110 \mathrm{~cm})$ Pacific bluefin tuna released from a tow pen (2001) in Monterey, CA. For comparison, fish released from Monterey in 1999 and 2000 are shown. In 2002, pop-up satellite tagged Pacific bluefin (white pentagon) and Lotek 2310, and Lotek 1100 archival-tagged tunas (white pentagon with circles) were released off Baja, Mexico (white x) and they either popped up or were recaptured. (B) Visualization of water column structure from depth temperature profiles with the LTD 2310 tag. (C) Depth movements of Pacific bluefin tuna based on the LTD2310 tag. Maximum depth in white and red indicates the depth where the bluefin resides $>2$ min time in every 6-h period. Data were acquired in 1-min intervals.

the calibrations of light- and SST-based geolocation techniques (e.g., Welch and Eveson, 1999) with archival and pop-up satellite tags through direct comparison with satellite-linked technologies. We will address the longevity of tag attachment to free-swimming animals. We have accelerated the development of two devices (GPS and CTD tags) for specific use in the TOPP program. A relatively small investment now will insure that the TOPP program will proceed after this new technology has been proven in the field.

Additionally, all programs involved with electronic tagging generate large amounts of data. We have initiated a collaborative effort to develop approaches and associated software to provide for data management, along with the visualization and analysis tools required to integrate tagcollected data with oceanographic data. Developing a common structure for integrated data management is the key to the success of TOPP. Thus, it is imperative that an integrated data management system and an initial version of the oceanographic toolkit be available from the start of the TOPP program.

\section{Steps toward oceanographic integration}

Meeting the objectives of TOPP will require careful integration of biological and physical data. The initial November 2000 TOPP workshop addressed environmental data requirements, data delivery systems, an "oceanographic toolkit" for data integration and visualization, and data management. Two follow up workshops (April and June 2002) were charged with identifying (1) the specific data requirements from the physical environment, (2) the data delivery systems to be used, and (3) a group of oceanographers interested in participating in the larger TOPP program. The working groups developed a series of recommendations that are currently being incorporated into the TOPP program, including.

1. that the structure of physical oceanography within the TOPP program should make the conceptual transition from having small oceanography groups in each lab to having a larger, centralized group that can work with all the biologists;

2. TOPP should have a local oceanography advisory group, plus three working groups in the areas of in situ observations, remote sensing, and modeling;

3. presentations on TOPP should be made at relevant oceanographic meetings (e.g., Epoc, CalCOFI, AGU) and

4. TOPP should collaborate with other programs, making use of ongoing oceanographic sampling programs on the West Coast, such as CalCOFI, Imecocal, PISCO, GLOBEC, MBARI, and others.

It was also emphasized that environmental data from tags are valuable to the oceanographic community, and can be incorporated into NODC data sets. Input from modelers is needed to insure that TOPP data products are valuable for model validation and assimilation. TOPP must insure that the precision and accuracy of sensors are known and adequate. Good salinity measurements are important for characterizing the physical environment used by the animals; recently developed salinity tags should be investigated to determine resolution and sensor drift. Light extinction from the tags, which can potentially be used to estimate primary production, should be investigated. An oceanographic toolkit, distinct from a data management and a visualization/analysis toolkit, should be developed for TOPP such that the oceanic structures and processes related to the behaviors of the various organisms might be synthesized. This activity should be housed at a central location with TOPP funded staff. Tag "environmental data" (location, depth, temperature, light level, salinity) should be rapidly processed and incorporated into the TOPP oceanographic toolkit, and filed as well within Ocean Data Centers for general use by all ocean scientists. A complete range of data types should be available to the users, and thus the 
National Virtual Ocean Data System (NVODS) should be available on the TOPP server. Other databases should also be integrated into the TOPP analysis system.

\section{Exporting the TOPP concept}

A goal of TOPP under the direction of the CoML is to establish a concept with the pilot project that can be exported to other regions of the sea. TOPP has already begun to realize the potential of a multispecies and multidisciplinary approach for examining regions of the ocean for exploration as well as biodiversity conservation. New projects using similar concepts are emerging. The TOPP scientific approach will be used potentially to support the establishment of a marine conservation corridor between the Galapagos Islands (Ecuador), Coco Islands (Costa Rica), Coiba Island (Panama), and several other islands of this region.

This region is a unique oceanographic region with remarkable biological diversity and a vision for a shared ecosystem management approach of the critical habitats in the Panama Bight and in the islands of the eastern Central Pacific regions of Ecuador, Panama, Columbia and Costa Rica is now emerging. This region has dynamic oceanographic forces and geological structures that have led to a unique array of species assemblages both on the islands and in the waters surrounding the region. Mankind has recognized the uniqueness of these habitats as they have been designated as two World Heritage Sites. The TOPP concept provides the scientific underpinning for a regional plan to study the local pelagic ecosystem from the top predators to those at the lowest level. The TOPP framework can be a key asset for exploring the biodiversity, critical habitats, distribution and abundance of key species in the region. Data from implementation of a localized TOPP program in the region can be used to assess the uniqueness of the species assemblages, their critical habitat and the range of the movements into and out of the ecosystem. TOPP's exploration of what types of tags, for what organism, logistics and oceanographic integration provides a ready made mix of tools for conducting a comprehensive survey of the pelagic ecosystem in this region as well as elsewhere. This approach can be readily applied to other oceanic regions and becomes increasingly important as the need for management of human resource extraction in pelagic seas forces upon us difficult choices.

\section{Acknowledgements}

The new scientific advances arising from the TOPP program could not have been possible without significant support. We thank Jesse Ausubel and the CoML Steering Committee for their vision in developing these programs. We thank the Sloan and Packard Foundations for support of the initial TOPP workshop and the planning phase of the project. A NOPP grant administered through the ONR is providing funds for new tag development. Finally, we thank the diverse group of scientists and engineers involved in TOPP for their cooperation and willingness to merge individual projects and new disciplines to meet the objectives of TOPP and the CoML. The Block and Costa Lab students and postdocs, D. Kohrs and H. Dewar have provided significant enthusiasm for the TOPP concept.

\section{References}

Andrews, R.D., Jones, D.R., Williams, J.D., Thorson, P.H., Oliver, G.W., Costa, D.P., Le Bœuf, B.J., 1997. Heart rates of northern elephant seals diving at sea and resting on the beach. J. Exp. Biol. 200, 2083-2095.

ATOC Consortium, 1998. Ocean climate change: comparison of Acoustic Tomography Satellite Altimetry, and Modeling. Science 281, 1327-1332.

Block, B.A., Dewar, H., Farwell, C., Prince, E.D., 1998a. A new satellite technology for tracking the movements of Atlantic bluefin tuna. Proc. Nat. Acad. Sci. USA 95, 9384-9389.

Block, B.A., Dewar, H., Williams, T., Prince, E.D., Farwell, C., Fudge, D.J., 37-43. Archival Tagging of Atlantic bluefin tuna (Thunnus thynnus thynnus). Mar. Techn. Soc. J. 32, 1998 b.

Block, B.A., Dewar, H., Blackwell, S.B., Williams, T., Prince, E., Boustany, A.M., Farwell, C., Fudge, D.J., Seitz, A., 2001. Migratory movements depth preferences and thermal biology of Atlantic bluefin tuna. Science 293, 1310-1314.

Block, B.A., Costa, D.P., Boehlert, G., Kochevar, R. A Report on the Tagging of Pacific Pelagics (TOPP) Workshop: A Pilot Project for the Census of Marine Life Monterey California, November 12-14, 2000, Available at www.toppcensus.org.

Boehlert, G.W., Costa, D.P., Crocker, D.E., Green, P., O’Brien, T., Levitus, S., Le Bœuf, B.J., 2001. Autonomous Pinniped environmental samples: using instrumented animals as oceanographic data collectors. J. Atmos. Ocean Technol. 18, 1882-1893.

Boustany, A., Davis, S., Anderson, S., Pyle, P., Block, B., 2002. Satellite tags reveal expanded ecological niche for white sharks in the north Pacific. Nature (London) 415 (6867), 35-36.

Burgess, W., Tyack, P., Le Bœuf, B.J., Costa, D.P., 1998. An intelligent acoustic recording tag first results from free-ranging northern elephant seals. Deep-Sea Res. II 45, 1327-1351.

Calambokidis, J., Steiger, G.H., Evenson, J.R., Flynn, K.R., Balcomb, K.C., Claridge, D.E., Bloedel, P., Straley, J.M., Baker, C.S., von Ziegesar, O., Dahlheim, M.E., Waite, J.M., Darling, J.D., Ellis, G., Green, G.A., 1996. Interchange and isolation of humpback whales off California and other North Pacific feeding grounds. Mar. Mammal Sci. 12, 215-226.

Campagna, C., Rivas, A.L., Marin, M.R., 2000. Temperature and depth profiles recorded during the dives of elephant seals reflect distinct ocean environments. J. Mar. Syst. 24, 299-312.

Charrassin, J. B., Park, Y.H., Le Maho, Y., 2002. Penguins as oceanographers unravel hidden mechanisms of marine productivity. Ecol. Lett. 5 (3), 317-319.

Costa, D.P., 1993. The Secret Life of Marine Mammals: novel tools studying their behavior and biology at sea. Oceanography 6 (3), 120-128.

Crocker, D.E., Le Bœuf, B.J., Costa, D.P., 1997. Drift diving in female northern elephant seals: implications for food processing. Can. J. Zool. 75, 27-39.

Delong, R.L., Stewart, B.S., 1991. Diving patterns of northern elephant seal bulls. Mar. Mammal Sci. 7, 369-384. 
Delong, R.L., Stewart, B.S., Hill, R.D., 1992. Documenting migrations of northern elephant seals using day length. Mar. Mammal Sci. 8, $155-159$.

Fernandez, P., Anderson, D.J., Sievert, P.R., Huyvaert, K.P., 2001. Foraging destinations of three low-latitude albatross (Phoebastria) species. J. Zool. (London) 254, 391-404.

Fiedler, P.C., Reilly, S.B., Hewitt, R.P., Demer, D., Philbrick, V.A., Smith, S., Armstrong, W., Croll, D.A., Tershy, B.R., Mate, B.R., 1998. Blue whale habitat and prey in the California Channel Islands. Deep-Sea Res. Part II 45 (8-9), 1781-1801.

Fletcher, S., Le Bœuf, B.J., Costa, D.P., Tyack, P.L., 1996. Onboard acoustic recording from diving elephant seals. J. Acoust. Soc. Am. 100 (4), 2531-2539.

Gunn, J., Block, B.A., 2001. Acoustic, archival and pop-up satellite tagging of tunas. In: Block, B.A., Stevens, E.D. (Eds.), Tunas: Ecological Physiology and Evolution. Academic Press, New Tork.

Hofman, E.E., Klinck, J.M., Costa, D.P., Daly, K.L., Torres, J.J., Fraser, W.R., 2002. U.S. Southern Ocean Global Ocean Ecosystems Dynamics Program. Oceanography 14, 67-74.

Hyrenbach, K.D., Fernandez, P., Anderson, D.J., 2002. Oceanographic habitats of two sympatric North Pacific albatrosses during the breeding season. Mar. Ecol. Progr. Ser. 233, 283-301.

Kitagawa, T., Nakata, H., Kimura, S., Itoh, T., Tsuji, S., Nitta, A., 2000. Effect of ambient temperature on the vertical distribution and movement of Pacific bluefin tuna revealed with archival tags. Mar. Ecol. Progr. Ser. 206, 251-260.

Le Boeuf, B.J., Costa, D.P., Huntley, A.C., Feldkamp, S.D., 1988. Continuous, deep diving in female northern elephant seals. Mirounga angustirostris Can. J. Zool., 446-458.

Le Bøuf, B.J., 1994. Variation in diving pattern of northern elephant seals with age, mass, sex, and reproductive condition. In: Le Bœuf, B.J., Laws, R.M. (Eds.), Elephant Seals: Population Ecology, Behavior, and Physiology. University of California Press, Berkeley, pp. 237-252.

Le Bœuf, B.J., Crocker, D.E., Costa, D.P., Blackwell, S.B., Webb, P.M., Houser, D.S., 2000. Foraging ecology of northern elephant seals. Ecol. Monogr. 70, 353-382.

Lutcavage, M.E., Brill, R.W., Skomal, G.B., Chase, B.C., Howey, P.W., 1999. Results of pop-up satellite tagging of spawning size class fish in the Gulf of Maine: do North Atlantic bluefin tuna spawn in the mid-Atlantic? Can. J. Fish. Aquat. Sci. 56, 173-177.

Marcinek, D.J., Blackwell, S.B., Dewar, H., Freund, E., Farwell, C., Dau, D., Seitz, A., Block, B.A., 2001. Depth movements and muscle temperatures of Pacific Bluefin Tuna measured with ultrasonic telemetry. Mar. Biol. 138, 869-881.
Mate, B.R., Gisiner, F., Mobley, J., 1998. Local and migratory movements of Hawaiian humpback whales tracked by satellite telemetry. Can. J. Zool. 76, 863-868.

Mate, B.R., Lagerquist, B.A., Calambokidis, J., 1999. Movements of North Pacific blue whales during the feeding season off southern California and their southern fall migration. Mar. Mammal Sci. 15, $1246-1257$.

McCafferty, D.J., Boyd, I.L., Walker, T.R., Taylor, R.I., 1999. Can marine mammals be used to monitor oceanographic conditions? Mar. Biol. 134, 387-395.

Nowlin, W.D., Briscoe, M., Smith, N., McPhaden, M.J., Roemmich, D., Chapman, P., Grassle, J.F., 2001. Evolution of a sustained ocean observing system. Bull. Amer. Met. Soc. 82 (7), 1369-1376.

Polovina, J.J., Kobayashi, D.R., Ellis, D.M., Seki, M.P., Balazs, G.H., 2000. Turtles on the edge: movement of loggerhead turtles (Caretta caretta) along oceanic fronts in the central North Pacific 1997-1998. Fish. Oceanogr. 9, 71-82.

Schaefer, K.M., Fuller, D.W., 2002. Movements, behavior, and habitat selection of bigeye tuna (Thunnus obesus), in the eastern equatorial Pacific, ascertained through archival tags. Fuller Fish. Bull. 100, 765-788.

Steele, J.H., 1998. From carbon flux to regime shift. Fish. Oceanogr. 7 (3-4), 176-181.

Stewart, B.S., De Long, R.L., 1995. Double migrations of the northern elephant seal. Mirounga angustirostrisl J. Mammal. 76, 196-205.

Urban, J.R., Alvarez, C.F., Salinas, M.Z., Jacobsen, J., Balcomb, K.C., Jaramillo, A.L., de Guevara, P.L.P., Aguayo, A.L., 1999. Population size of humpback whale Megaptera novaeangliae in waters off the Pacific coast of Mexico. Fish. Bull. (Washington, DC) 97, 1017-1024.

Weimerskirch, H., Wilson, R.P., Koudil, M., 1995. The use of seabirds to monitor sea surface temperature and validate satellite remote sensing measurements in the southern ocean. Mar. Ecol. Progr. Ser. 126, 229-303.

Welch, D.W., Eveson, J.P., 1999. An assessment of light-based geoposition estimates from archival tags. Can. J. Fish. Aquat. Sci. 56, $1317-1327$.

Wilson, R.P., 1992. Environmental monitoring with seabirds: do we need additional technology? S. Afr. J. Mar. Res. 12, 919-926.

Wilson, R.P., Gremillet, D., Syder, J., Kierspel, M.A.M., Garthe, S., Weimerskirch, H., Schafer-Neth, C., Scolaro, J.A., Bost, C.A., Plotz, J., Nel, D., 2002. Remote-sensing and seabirds: their use abuse and potential for measuring marine environmental variables. Mar. Ecol. Progr. Ser. 228, 241-261. 